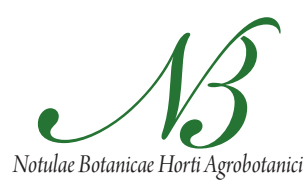

Cluj-Napoca

\title{
Modelling of the Faba bean (Vicia faba L.) Sprouting Reaction to Temperature in Farm Condition
}

\author{
Hosein AJAM NOROUZI', Farshid VAZIN²* \\ I Islamic Azad University, Gorgan branch, Gorgan,Iran; ajamnorozei@yahoo.com \\ ${ }^{2}$ Islamic Azad University, Gonabad branch, Gonabad,Iran; farshidvazin@gmail.com (corresponding author)
}

\begin{abstract}
The main goal of this study is to developa Faba bean plant sprouting model that includes a cardinal temperature determination and a required biologic day for Faba bean sprouting ( or to determine the Faba bean sprouting reaction to temperature). For this purpose, in a farm test, 4 cultivars of Faba bean plants ('Barekat,' 'Saraziri,' 'Eraghi' and 'Gavi') were cultivated on 11 sowing dates (one in each month ) and the required days to their sprouting were recorded. Beta, curve, quadratic and Sawtooth models were used to describe relationship between the sprouting rate and the temperature. To select the best model, it has been used an average root mean square deviation (RMSD), an R square $\left(\mathrm{R}^{2}\right)$, simple linear regression coefficients ( $\mathrm{a}$ and $\mathrm{b}$ ) and a correlation coefficient $(\mathrm{r})$. The results showed that the Faba bean sprouting reaction to temperature was better described by a Piecewise function. The estimation of the cardinal temperature by a Piecewise function indicated that the base temperature varies from $0.98^{\circ} \mathrm{C}$ to $1.61^{\circ} \mathrm{C}$, and the optimum temperature varies from $24.99^{\circ} \mathrm{C}$ to $28.8^{\circ} \mathrm{C}$ for the different cultivars of Faba bean plants, but the ceiling temperature for all the cultivars was estimated at 35 degree centigrade. Also, the required biologic day estimation for sprouting as determined by the Piecewise model showed a significant difference between the cultivars, as the 'Gavi' cultivars (which are smaller) germinated after 6.65 days (maximum rate is 0.09 ). For the other cultivars, the required biologic day fell between 8.60 and 9.31 days. The obtained data can be used to predict Faba bean sprouting in different temperature conditions.
\end{abstract}

Keywords: Faba bean, sprouting, temperature, modelling

\section{Introduction}

Faba beans (Vicia faba L), with a cultivated area of 2.9 million hectares, are a significant world legume. In the Middle East, China and even in some regions of Europe, this plant serves as a protein source for human and animals foods (Ellis et al., 1987; Yin et al., 1995). The Faba-beancultivated area in Iran is approximately 30,000 hectares (FAO, 2005). Golestan, Khozestan, Mazandaran and Gilan are the main production areas of Faba beans (Soltani et al., 2006a). Due to the population growth and the unavailability of other protein sources, the demand for Faba beans is increasing (Turpin et al., 2002). The selection of a suitable sowing date and the right placement of plants are among the factors affecting the plant's performance. To increase production and achieve a better placement of the plants, a high rate and uniform sprouting of this plant is necessary (Iannucci et al., 2000). Temperature and humidity have significant effects on these features (Anda and Pintel, 1994; Jacobsen and Bach, 1998). In the Iranian climate, the soil humidity at the sowing date is not a constraint, and temperature is the main factor determining sprouting and plant placement. Understanding the cardinal temperatures (base, desirable and ceiling) and surveying the seeds' sprouting reaction to temperature are significant because the information can be used to create prediction models for sprouting, selection of a suitable sowing date, cultivar screening and genotypes to sustain the plants in extreme temperatures (Jacobsen and Bach, 1998; Ramin, 1997). There are no reports about the sprouting cardinal temperatures of Faba beans and no research about Iranian cultivars. Therefore, the purpose of this report is to quantify the sprouting reaction of Faba beans to temperature under farm conditions.

\section{Materials and methods}

This test was implemented in 2005 and 2006 in GORGAN, an agricultural research station with northern latitude $39^{\circ} 45^{\circ}$, eastern latitude $54^{\circ} 25^{\prime}$ and located 5.5 metres above sea level. The land was ploughed after wheat cropping in 2004, and in the summer of 2005, it was ready to plough. The test included 11 dates for sowing: 4 August, 1 September, 2 October, 31 October, 30 November and 31 December, 2005, and 31 January, 1 March, 30 March, 28 April and 28 May, 2006. On each sowing date, a test was conducted as a Randomised Complete Blocks design with 4 repetitions. Each block included 4 cultivars of Faba beans from different regions of Iran, including 'Barekat' (the main cultivar of Golestan), 'Saraziri' (the main cultivar of Khozestan), 'Gavi' (the main cultivar of Lorestan) and 'Eraghi' (the typical cultivar of Golestan). Each 1000- 
180

grain weight, respectively, was $1320,1250,1200$ and 520 grams. The length of each cert was 4 metres, composed of 3 sowing lines that were 60 centimetres away from each other. Two metres in each cert were selected randomly, and the number of germinated seeds was recorded. Germinated seeds are seeds in which any part of the plant can be detected on the land surface. On all sowing dates and for each cultivar, the required time for $50 \%$ sprouting (the required time for $50 \%$ of the seeds to sprout, for example, 66 seeds out of 132 seeds in a cert) was recorded. Then, the inverse of the required time for $50 \%$ sprouting was calculated as the sprouting rate. At the end of the test, a combined analysis of a Randomised Complete Blocks design was used for data variance analysis. Calculations of data variance analysis were conducted by SAS software (Soltani et al., 2006b).

For describing relation between temperature and sprouting rate and estimation of biologic day and cardinal temperature, following model was used:

$$
1 / e=f(T) / e_{0}
$$

Where:

$1 / e=$ sprouting rate

$f(T)=$ temperature function

$e_{0}=$ biologic days for sprouting (Fig. 1):

$$
\begin{aligned}
& \text { 1. Piecewise function (Soltani et al., 2006a): } \\
& f(T)=\frac{\left(\begin{array}{ll}
T & T_{b}
\end{array}\right)}{\left(\begin{array}{ll}
T_{o} & T_{b}
\end{array}\right)} \quad \text { if } \quad T_{b}<T \leq T_{o} \\
& f(T)=\frac{\left(\begin{array}{ll}
T_{c} & T
\end{array}\right)}{\left(\begin{array}{ll}
T_{c} & T_{o}
\end{array}\right)} \quad \text { if } \quad T_{o}<T<T_{c} \\
& f(T)=0 \quad \text { if } \quad T \leq T_{b} \text { or } T \geq T_{c}
\end{aligned}
$$

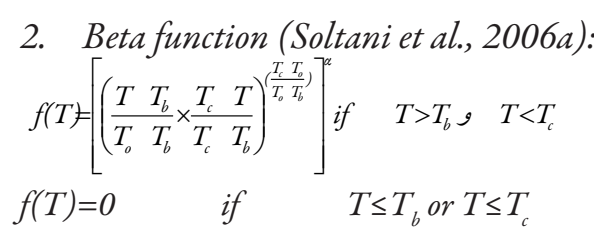

3. Quadratic function (Soltani et al., 2006a): $\left.f(T)=\left[\begin{array}{lll}T & \left.T_{b}\right) \times\left(T_{c}\right. & T) \times\left(\frac{T_{c}}{T_{b}}\right. \\ 2\end{array}\right)^{2}\right]$

\section{Curve function (Soltani et al., 2006a):}

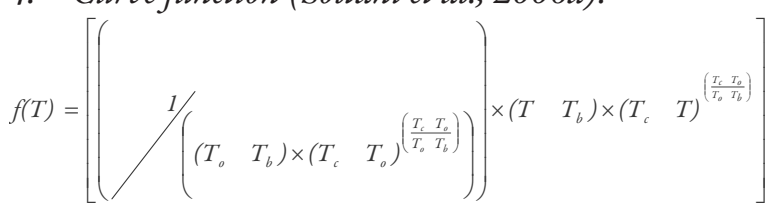

5. Saw tooth function (Soltani et al., 2006a):

$$
\begin{array}{lll}
f(T)=\frac{\left(\begin{array}{ll}
T & T_{b}
\end{array}\right)}{\left(\begin{array}{ll}
T_{01} & T_{b}
\end{array}\right)} & \text { if } & T_{b}<T<T_{01} \\
f(T)=\frac{\left(\begin{array}{ll}
T_{c} & T
\end{array}\right)}{\left(\begin{array}{ll}
T_{c} & T_{02}
\end{array}\right)} & \text { if } & T_{02}<T<T_{c} \\
f(T)=1 & \text { if } & T_{01} \leq T \leq T_{02} \\
f(T)=0 & \text { if } & T \leq T_{b} \text { or } T \geq T_{c}
\end{array}
$$

In above functions $T, T_{O Z}, T_{O P}, T_{,}, T$ are respectively average air temperature from sowing to sprouting, base temperature, optimum temperature, minimum optimum temperature, maximum optimum temperature and Ceiling temperature. Ceiling temperature in this study was considered a constant value of 35 degree centigrade. In addition, 35 degree centigrade is accepted as a high biologic limit for cold friendly plants like Faba bean. Estimation of each model's parameters was carried out by SAS software. Also, for selecting best model among different models criteria like average Root mean square deviation (RMSD), $R$ square $\left(R^{2}\right)$, simple linear Regression coefficients ( $a$ andb) and correlation coefficient (r) was used. For comparing values of estimated parameters by different models among various cultivars, double of standard error (SE) was used which coincide to safety limit concepts of $95 \%$ (Soltani $e t$ al., 2006a).

\section{Results and discussion}

The range of temperature for the tests was $5^{\circ} \mathrm{C}$ to $37^{\circ} \mathrm{C}$, and the minimum temperature ranged from $-2^{\circ} \mathrm{C}$ to $28^{\circ} \mathrm{C}$ (Fig. 2). This wide range of temperature indicates the success of the test in recording the variation in temperature. The results of the variance analysis showed a significant difference (probability level of 0.1) among the sowing dates with respect to temperature, days of sprouting and sprouting rate (Tab. 1). In addition, the results of the average comparison using an LSD test showed that August (with an average temperature of 29.7 degree centigrade) was the hottest month and DAY (with an average temperature of 6.3 degree centigrade) were the coolest months of the test. September had the minimum required days to sprouting (8.3 days), and the sowing date of day ( 40 days) required the longest time for sprouting. The maximum rate of sprouting was found in September (0.125), and the minimum rate was found in day (0.025) (Fig. 3). The results of the variance analysis indicated a significant difference between the different cultivars of Faba beans with respect to the number of days for sprouting and the sprouting rate (Tab. 1). Comparing the cultivars by an LSD test showed that the 'Gavi' cultivar had the minimum number of days for sprouting (14.3 days) and the maximum sprouting rate (0.09 day) (Fig. 4). The reason that the 'Gavi' cultivar needed fewer days for sprouting is because of its smaller seeds. The weight of 1000 'Gavi' seeds was 520 grams but for other cultivars, the weights ranged between 1200 to 1320 grams. Therefore, this shows diversity between the Faba bean genotypes in terms of the sprouting rate. This diversity in sprouting rate matches the results suggested by Turpin et al. (2003). Tab. 2 shows the parameters of the models' reliability evaluation. Fig. 5 shows the observed and predicted days to sprouting in a farm test. The selection of a suitable model requires two steps. First, it has been chosen the models in which the prediction has no bias; namely, the values of $\mathrm{a}$ and $\mathrm{b}$ are not significant. In 

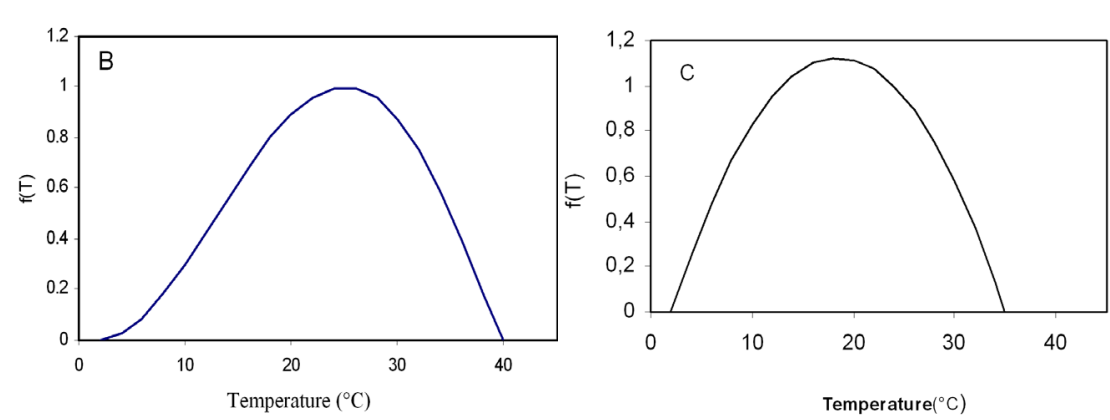

181
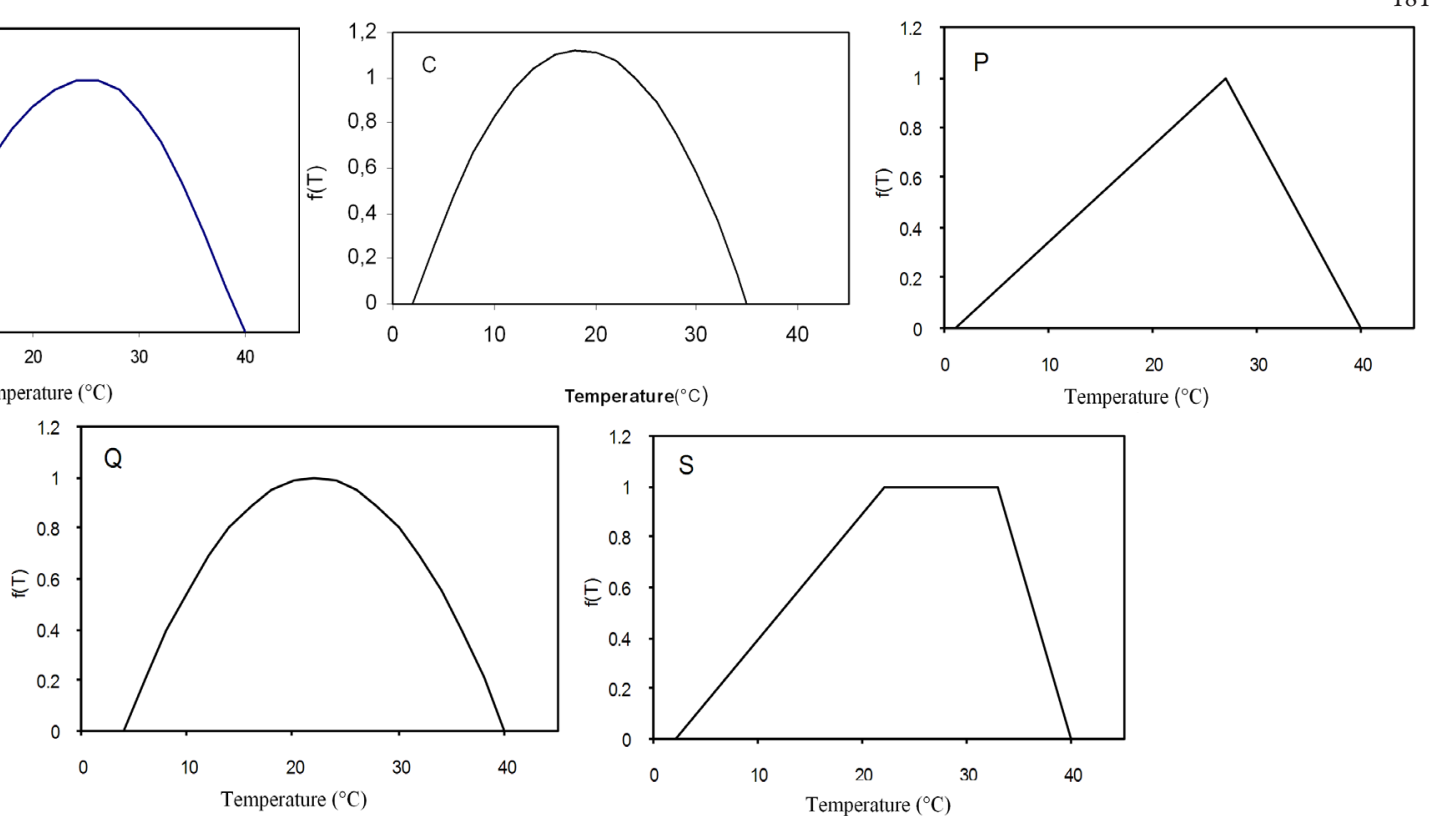

Fig. 1. Used Functions for sprouting to temperature reaction modeling include: $\beta$-function (B), Piecewise function (P), Quadratic function (Q), Curves function(C) and Saw tooth function(S)

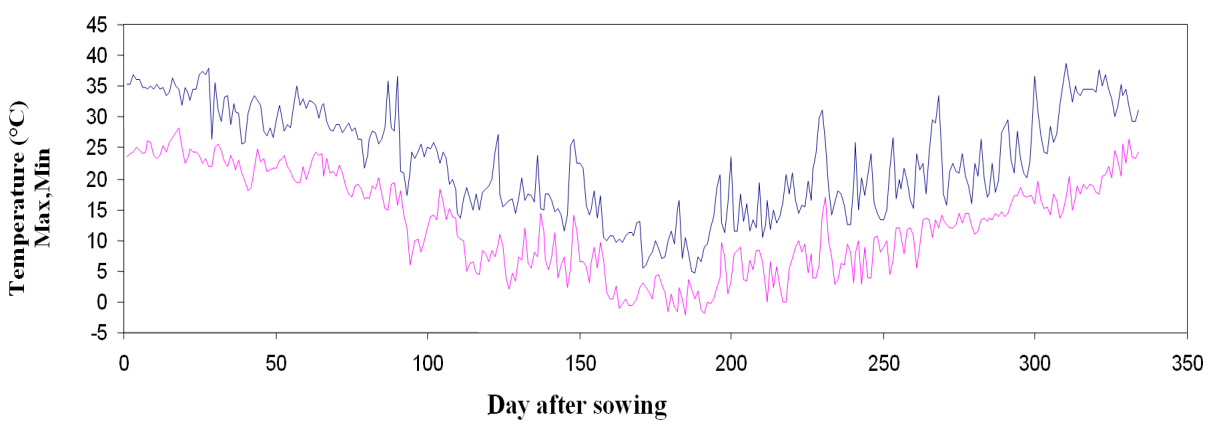

Fig. 2. Maximum and minimum temperature during experimental in Gorgan, Iran. Straight lines shows sowing date

the second step, it has been selected between the successful models of the first step that justify a larger part of the variations (larger $\mathrm{R}^{2}$ ) and simultaneously by RMSD show a smaller error and a high correlation between the observed and predicted values. Among the different models, only the Piecewise model shows no significant bias for the different cultivars, and the beta model prediction shows a significant bias only for the 'Eraghi' Faba bean. Therefore, the beta and Piecewise models were selected in the first step, and the others were omitted. The performances of these two models were the same with respects to the RMSE, $\mathrm{R}^{2}$ and $\mathrm{r}$ analyses (Tab. 2). But the beta model has no acceptable reliability for the 'Eraghi' cultivars, and estimating a ratio for the base temperature with this model for the 'Eraghi' and 'Barekat' cultivars produced impossible values (Tab. 3). By attention to these points, the final and best model was determined to be the Piecewise model. The estimated parameters for all the models are provided for

Tab. 1. Analysis of variance for temperature, day until sprouting and sprouting date of faba bean (Vicia faba L.) based on experiments combined analysis

\begin{tabular}{|c|c|c|c|c|c|c|c|}
\hline \multirow{2}{*}{ SOV } & \multirow{2}{*}{$\mathrm{df}$} & \multicolumn{2}{|c|}{ Temperature } & \multicolumn{2}{|c|}{ Day until sprouting } & \multicolumn{2}{|c|}{ Sprouting rate } \\
\hline & & Prob & SS & Prob & SS & Prob & SS \\
\hline Sowing date & 10 & $<0.0001$ & 8846.24 & $<0.0001$ & 12607.85 & $<0.0001$ & 0.13 \\
\hline Error(a) & 33 & 0.4857 & 3.16 & 183.19 & 44.44 & 0.6074 & 0.002 \\
\hline Genotype & 3 & 0.0036 & 1.39 & $<0.0001$ & 282.74 & $<0.0001$ & 0.14 \\
\hline \multicolumn{8}{|l|}{ Sowing date } \\
\hline Genotype & 30 & $<0.0001$ & 20.62 & $<0.0001$ & 183.19 & $<0.0001$ & 0.015 \\
\hline Error(b) & 99 & ------- & 20.51 & ------- & 126.81 & ------- & 0.007 \\
\hline
\end{tabular}


182

Tab. 2. Root mean square deviation (RMSD), variable coefficient (CV), R square $\left(\mathrm{R}^{2}\right)$ for different descriptive models relationship between sprouting rate with temperature in four faba bean (Vicia faba L.) cultivars

\begin{tabular}{|c|c|c|c|c|c|c|c|}
\hline Temperature function & Cultivar & RMSD & $\mathrm{CV}$ & $\mathrm{R}^{2}$ & $\mathrm{a} \pm \mathrm{SE}$ & $\mathrm{b} \pm \mathrm{SE}$ & $\mathrm{r}$ \\
\hline \multirow{4}{*}{$\beta$} & 'Barekat' & 2.53 & 14.84 & 0.79 & $-0.49 \pm 0.83$ & $1.02 \pm 0.04$ & 0.96 \\
\hline & 'Saraziri' & 2.03 & 12.24 & 0.88 & $0.04 \pm 0.68$ & $0.99 \pm 0.04$ & 0.97 \\
\hline & 'Eraghi' & 2.20 & 12.94 & 0.82 & $3.39 \pm 0.77^{*}$ & $0.77 \pm 0.04^{*}$ & 0.95 \\
\hline & 'Gavi' & 2.15 & 15.34 & 0.75 & $-0.14 \pm 0.63$ & $0.99 \pm 0.04$ & 0.97 \\
\hline \multirow{4}{*}{ Piecewise } & 'Barekat' & 2.48 & 14.57 & 0.77 & $0.35 \pm 0.81$ & $0.97 \pm 0.042$ & 0.96 \\
\hline & 'Saraziri' & 2.55 & 15.05 & 0.72 & $0.49 \pm 0.85$ & $0.98 \pm 0.045$ & 0.96 \\
\hline & 'Eraghi' & 2.37 & 13.13 & 0.84 & $0.03 \pm 0.72$ & $1.03 \pm 0.043$ & 0.96 \\
\hline & 'Gavi' & 2.02 & 14.34 & 0.75 & $0.84 \pm 0.59$ & $0.92 \pm 0.041$ & 0.97 \\
\hline \multirow{4}{*}{ Quadratic } & 'Barekat' & 240.02 & 154.46 & 0.54 & $-577.30 \pm 78.50^{*}$ & $42.76 \pm 4.07^{*}$ & 0.85 \\
\hline & 'Saraziri' & 622.68 & 372.56 & 0.63 & $-710.60 \pm 207.7^{*}$ & $52.54 \pm 11.1^{*}$ & 0.58 \\
\hline & 'Eraghi' & 28.00 & 80.44 & 0.56 & $-84.57 \pm 9.83^{*}$ & $6.79 \pm 0.51^{*}$ & 0.90 \\
\hline & 'Gavi' & 18.04 & 161.53 & 0.28 & $46.37 \pm 5.27^{*}$ & $-3.17 \pm 0.32^{*}$ & 0.84 \\
\hline \multirow{4}{*}{ Curve } & 'Barekat' & 4.91 & 27.05 & 0.75 & $-6.85 \pm 1.61^{*}$ & $1.46 \pm 0.08^{*}$ & 0.94 \\
\hline & 'Saraziri' & 2.73 & 16.10 & 0.87 & $-2.12 \pm 0.91^{*}$ & $1.41 \pm 0.05^{*}$ & 0.96 \\
\hline & 'Eraghi' & 2.89 & 16.27 & 0.78 & $-2.41 \pm 1.01^{*}$ & $1.15 \pm 0.05^{*}$ & 0.96 \\
\hline & 'Gavi' & 2.47 & 17.35 & 0.75 & $-1.22 \pm 0.72^{*}$ & $1.08 \pm 0.04^{*}$ & 0.97 \\
\hline \multirow{4}{*}{ Saw tooth } & 'Barekat' & 3.37 & 19.15 & 0.79 & $-3.41 \pm 1.10^{*}$ & $1.23 \pm 0.06^{*}$ & 0.96 \\
\hline & 'Saraziri' & 2.05 & 12.33 & 0.87 & $-0.08 \pm 0.68$ & $1.00 \pm 0.04^{*}$ & 0.97 \\
\hline & 'Eraghi' & 2.12 & 12.28 & 0.83 & $1.65 \pm 0.74^{*}$ & $0.89 \pm 0.04^{*}$ & 0.96 \\
\hline & 'Gavi' & 2.78 & 19.19 & 0.83 & $-2.21 \pm 0.81^{*}$ & $1.17 \pm 0.05^{*}$ & 0.96 \\
\hline
\end{tabular}

*, for a coefficient, its showing significant different is with zero and for b coefficient, significant different has been presented with 1
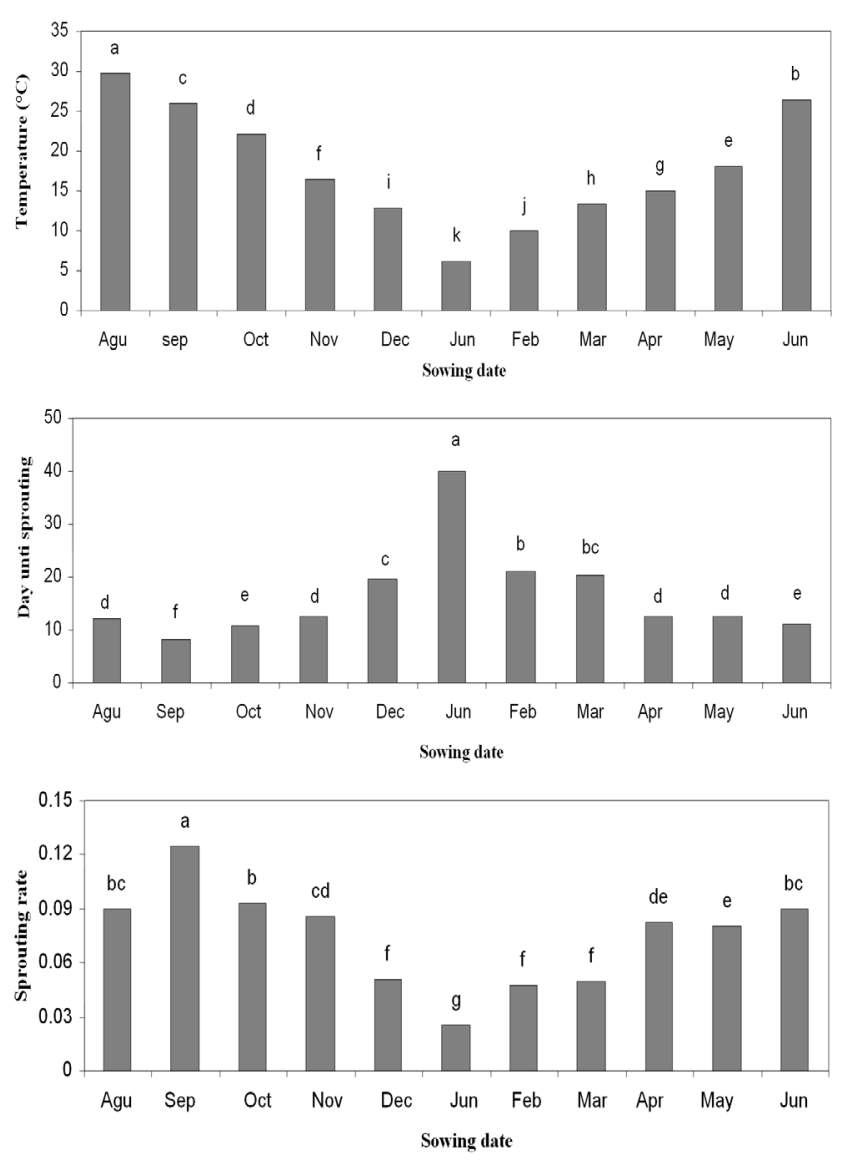

Fig. 3. Mean of temperature, day until sprouting and sprouting rate for sowing different dates comparison in Tab. 3. The Piecewise model justified 72 to $84 \%$ of the sprouting rate versus temperature estimates for the different cultivars, and the value of the RMSE for this model was between 2.02 to 2.55 days, which represents 13 to $15 \%$ of the average sprouting rate. It can then be said that the prediction capability of this model is acceptable. These findings agree with the findings of researchers such as Olsen et al. (1993) and Robertson et al. (2002a). They suggested that the Piecewise function is a good tool for describing the sprouting reaction and detection rate of leaves to temperature in different plants. Tab. 3 shows an estimation of the required cardinal temperature and biologic day for Faba bean sprouting. In accordance with the Piecewise model estimation, there is no significant difference between the Faba bean cultivars in terms of temperature. The base temperature for the 'Barekat,' 'Eraghi' and 'Gavi' cultivars, respectively, were estimated as: 1.00, 1.00, 0.98 and $1.61^{\circ} \mathrm{C}$.

Robertson et al. (2002b) suggested that the base temperature of Faba beans is $0^{\circ} \mathrm{C}$ to $1^{\circ} \mathrm{C}$. Despite the base temperature, there is a significant difference between the Faba bean cultivars in terms of the optimum temperature for seed sprouting. The optimum temperature for the 'Barekat', 'Saraziri', 'Eraghi' and 'Gavi' cultivars, respectively, were: $25.54^{\circ} \mathrm{C}, 25.63^{\circ} \mathrm{C}, 24.99^{\circ} \mathrm{C}$ and $28.82^{\circ} \mathrm{C}$. Manschadi et al. (1998) suggested that the optimum temperature for sprouting is 27 degree centigrade. In this regard, the differences among the 'Barekat', 'Saraziri' and 'Gavi' cultivars were not significant, but the optimum temperature for the 'Gavi' cultivar is significant and higher than the other 
Tab. 3. Evaluation fixed coefficient $\left(a\right.$, for $\beta$-function), basic temperature $\left(T_{b}\right)$, optimum temperature $\left(T_{0}\right)$, minimum optimum temperature $\left(\mathrm{T}_{01}\right)$, maximum optimum temperature $\left(\mathrm{T}_{02}\right)$ and day number of biological $\left[\mathrm{E}_{0}\right.$ for sprouting with different models in four faba bean (Vicia faba L.)] cultivars. Ceiling temperature $\left(\mathrm{T}_{\mathrm{c}}\right)$ in $35^{\circ}$ was considered fixed

\begin{tabular}{|c|c|c|c|c|c|c|}
\hline Temperature function & Cultivar & $\mathrm{a}$ & $\mathrm{T}_{C} \pm \mathrm{SE}$ & $\mathrm{T}_{\mathrm{b}} \pm \mathrm{SE}$ & $\mathrm{T}_{0} \pm \mathrm{SE}$ & $\mathrm{E}_{0}$ \\
\hline \multirow{4}{*}{$\beta$} & 'Barekat' & $5.03 \pm 5.38$ & 35.00 & $-17.10 \pm 30.07$ & $23.78 \pm 0.51$ & $9.72 \pm 0.39$ \\
\hline & 'Saraziri' & $2.01 \pm 1.29$ & 35.00 & $-4.70 \pm 10.16$ & $26.16 \pm 0.84$ & $9.83 \pm 0.28$ \\
\hline & 'Eraghi' & $1.06 \pm 1.92$ & 35.00 & $-3.52 \pm 39.00$ & $24.32 \pm 0.39$ & $10.42 \pm 0.32$ \\
\hline & 'Gavi' & $1.30 \pm 0.97$ & 35.00 & $0.56 \pm 7.74$ & $28.01 \pm 2.32$ & $7.69 \pm 0.34$ \\
\hline \multirow{4}{*}{ Piecewise } & 'Barekat' & & 35.00 & $1.61 \pm 1.41$ & $24.99 \pm 0.47$ & $8.60 \pm 0.33$ \\
\hline & 'Saraziri' & & 35.00 & $0.98 \pm 1.33$ & $25.63 \pm 0.39$ & $8.66 \pm 0.26$ \\
\hline & 'Eraghi' & & 35.00 & $1.00 \pm 1.02$ & $25.94 \pm 0.28$ & $9.31 \pm 0.20$ \\
\hline & 'Gavi' & & 35.00 & $1.00 \pm 0.98$ & $28.82 \pm 0.43$ & $6.65 \pm 0.21$ \\
\hline \multirow{4}{*}{ Quadratic } & 'Barekat' & & 35.00 & $6.34 \pm 0.54$ & $8.41 \pm 0.49$ & $10.48 \pm 0.43$ \\
\hline & 'Saraziri' & & 35.00 & $6.37 \pm 0.59$ & $8.40 \pm 0.54$ & $10.42 \pm 0.48$ \\
\hline & 'Eraghi' & & 35.00 & $6.04 \pm 0.55$ & $8.70 \pm 0.50$ & $11.27 \pm 0.45$ \\
\hline & 'Gavi' & & 35.00 & $6.60 \pm 0.70$ & $7.47 \pm 0.59$ & $8.34 \pm 0.47$ \\
\hline \multirow{4}{*}{ Curve } & 'Barekat' & & 35.00 & $4.33 \pm 0.96$ & $24.28 \pm 0.92$ & $10.52 \pm 0.34$ \\
\hline & 'Saraziri' & & 35.00 & $2.62 \pm 1.06$ & $27.38 \pm 1.05$ & $9.99 \pm 0.28$ \\
\hline & 'Eraghi' & & 35.00 & $2.53 \pm 1.07$ & $24.68 \pm 0.91$ & $11.35 \pm 0.32$ \\
\hline & 'Gavi' & & 35.00 & $2.75 \pm 1.63$ & $28.86 \pm 1.81$ & $7.68 \pm 0.39$ \\
\hline & & $\mathrm{T}_{\mathrm{h}} \pm \mathrm{SE}$ & $\mathrm{T}_{C} \pm \mathrm{SE}$ & $\mathrm{T}_{01} \pm \mathrm{SE}$ & $\mathrm{T}_{02} \pm \mathrm{SE}$ & $\mathrm{E}_{0}$ \\
\hline \multirow{4}{*}{ Saw tooth } & 'Barekat' & $2.99 \pm 1.24$ & 35.00 & $19.85 \pm 1.09$ & $27.89 \pm 0.70$ & $10.28 \pm 0.40$ \\
\hline & 'Saraziri' & $0.93 \pm 1.41$ & 35.00 & $22.22 \pm 1.27$ & $29.60 \pm 0.33$ & $10.08 \pm 0.30$ \\
\hline & 'Eraghi' & $0.48 \pm 1.61$ & 35.00 & $21.59 \pm 1.34$ & $27.36 \pm 0.64$ & $10.75 \pm 0.34$ \\
\hline & 'Gavi' & $2.74 \pm 1.64$ & 35.00 & $20.93 \pm 1.48$ & $30.51 \pm 0.00$ & $8.17 \pm 0.34$ \\
\hline
\end{tabular}
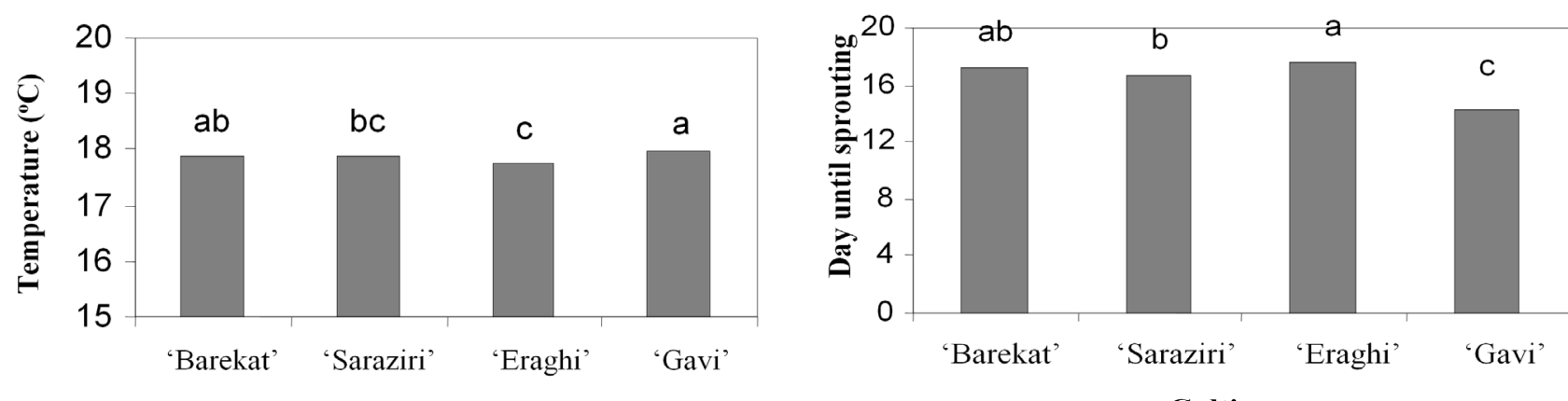

Cultivar

Cultivar

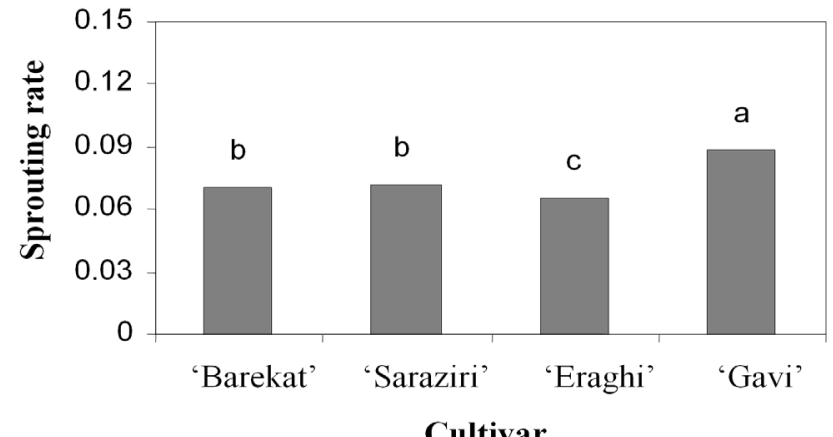

Fig. 4. Mean of temperature, day until sprouting and sprouting rate for different cultivars of Faba bean

three cultivars. Soltani et al. (2006b) suggested that the optimum sprouting temperature of chickpeas in GORGAN is $27.6^{\circ} \mathrm{C}$ to $30.4^{\circ} \mathrm{C}$. Ellis et al. (1987) reported that the desirable temperature by linear regression for sprouting the different cultivars of Faba beans was between $20^{\circ} \mathrm{C}$ to $26^{\circ} \mathrm{C}$. Covell et al. (1986) reported the desirable temperature for the sprouting of lens is between $24^{\circ} \mathrm{C}$ to $24.4^{\circ} \mathrm{C}$.
Also, the estimation of the required biologic day for sprouting determined by the Piecewise model indicated a significant difference among the Faba bean cultivars so that the number of required days for sprouting for the 'Barekat,' 'Saraziri' and 'Eraghi' cultivars, respectively, are: 8.60, 9.31 and 8.67 days, which are all longer than the re- 

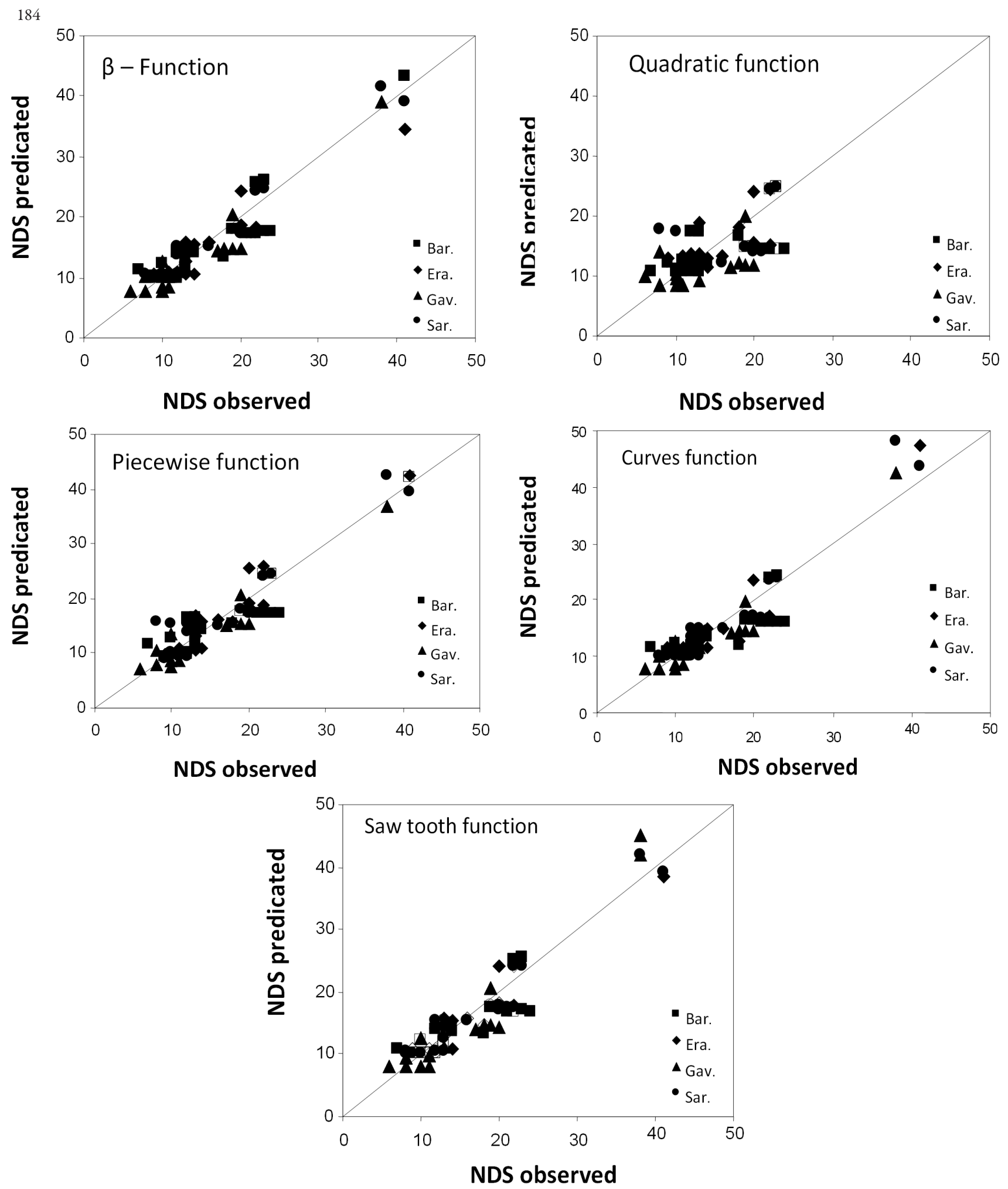

Fig. 5. Amounts observed days number until sprouting opposite its predicted in 'Barekat' (Bar), 'Eraghi' (Era), 'Gavi' (Gav) and 'Saraziri' (Sar) cultivars that used to with $\beta$, Quadratic piecewise, curve and sawtooth models

quired biologic days for the 'Gavi' cultivar (6.65 days). It seemed that the reason for the high rate of sprouting of the 'Gavi' cultivar is because the seeds are smaller. The ratio of the surface area to the volume in 'Gavi' seeds is higher, causing an increase in water absorption and a faster rate of sprouting for these seeds. Soltani et al. (2006b) suggested that the biologic day for sprouting of the different cultivars of chickpeas, determined by a Sawtooth model, is 6.1 days.

Soltani et al. (2006a) obtained the following relationship in GORGAN conditions between soil and air temperature: 0.046x-0.1616, which was in accordance with 12 
annual sowings (one per month) in a silt-clay soil where y represents the average temperature of the soil at a depth of $4 \mathrm{~cm}$, and $\mathrm{x}$ represents the average temperature of the air. By substituting the cardinal temperatures shown in Tab. 3 in the above equation, the cardinal temperatures can be obtained based on the soil temperature for each cultivar. For example, using the above equation, the base temperature, optimum temperature and ceiling temperature for the 'Barekat' sprouting, based on the soil and the estimated cardinal temperatures determined by the Piecewise model (Tab. 3), are: $36.24^{\circ} \mathrm{C}, 25.83^{\circ} \mathrm{C}$ and $1.51^{\circ} \mathrm{C}$, respectively. Jame and Cutforth (2004) used the air temperature to obtain suitable prediction data for wheat sprouting.

\section{Refrences}

Anda A, Pinter L (1994). Sorghum sprouting and development as influenced by soil temperature and water content. Agron J 86:621-624.

Covell S, Ellis RH, Roberts EH, Summerfield RJ (1986). The influence of chickpea, lentil, soybean and cowpea at constant temperature. J Exp Bot 37:705-715.

Ellis RH, Simon G, Covell S (1987). The influence of temperature on seed sprouting rate in grain Legumes. III. A Comparison of five faba bean genotypes at constant temperatures using a new screen method. J Exp Bot 38:1033-1043.

FAO (2005). Production Year Book, 2004. Food and Agriculture Organization of the United Nations (FAO), Rome, Italy. http://apps.Fao.Org.

Iannucci A, Difonzo N, Martinello P (2000). Temperature requirements for seed sprouting in four annul clovers grown under two irrigation treatments. Seed Sci Technol 28:5966.

Jacobsen SE, Bach AP (1998). The influence of temperature on seed sprouting rate in quinoa ( Chenopodium quinoa W.). Seed Sci Technol 26:515-523.

Jame YW, Cutforth HW (2004). Simulating the effect of temperature and sowing depth on sprouting and emergence of spring wheat. Agric Meteorol 124:207-218.
Manschadi AM, Sauerborn J, Stutzel H, Gobel W, Saxena MC (1998). Simulation of faba bean (Vicia faba L.) root system development under Mediterranean conditions. Eur J Agron 9:259-272.

Olsen JK, McMahon CR, Hamer GL (1993). Prediction of sweet corn phenology in subtropical environments. Agron J 85:410-415.

Ramin AA (1997). The influence of temperature on sprouting of taree irani (Allium ampeloprasum L. ssp iranicum W.). Seed Sci Technol 25:419-426.

Robertson MJ, Carberry PS, Huth NI, Turpin JE, Probert ME, Poulton PL, Bell M, Wright GC, Yeates SJ, Brhnsmead RB (2002a). Simulation of growth and development of diverse legume species in APSIM. Aust J Agric Res 53:429-446.

Robertson MJ, Watkinson A, Kierkegaard R, Holland JA, Potter JF, Burton TD, Walton W, Moot GH, Wratten DJ, Farre NI, Asseng S (2002b). Environmental and genotypic control of time to flowering in canola and Indian mustard. Aust J Agric Sci 53:793-809.

Soltani A, Hammer GL, Torabi B, Kobertson MJ, Zeinali E (2006a). Modeling. Chickpea: growth and development: Phonological development. Field Crops Res 99:1-13.

Soltani A, Robertson MJ, Torabi B, Yousefi Daz M, Sarparast $\mathrm{R}$ (2006b). Modeling seedling emergence in chickpea as in fluenced by temperature and sowing depth. Agric Meteorol 138:156-167.

Turpin JE, Robertson MJ, Hillcoat NS, Herridage DE (2002). Fababean (Vicia faba L.) in Australia,s northern grains belt: canopy development, biomass and nitrogen accumulation and partitioning. AUH J Agric53:227-237.

Turpin JE, Robertson MJ, Haire C, Bellotti WD, Moore AD, Rose I (2003). Simulating faba bean development, growth and yield in Australia. Agric Res 54:39-52.

Yin X, Kropff MJ, Mclaren G, Visperas RM (1995). A nonlinear model for crop development as a function of temperature. Agric Meteorol 77:1-16. 